from sea-sickness. He also thought he had prevented an attack in himself while crossing the English Channel by setting up a counter-irritation in the canals.

The objection is always offered to every theory which attempts to explain the cause of sea-sickness, that these theories do not account for the fact that some persons are never sick on the water. 'This can not be considered a valid objection for so many things must be taken into account - the constitution of the individual, etc. But for my part, I have never known an instance where a person of average sensibility going to sea for the first time has not felt, at least, a little disturbed until he has learned to let his abdominal muscles take care of themselves without the intervention of his will.

'The question arises how all the phenomena of seasickness have a tendency to pass away. They pass away for this reason: We learn to walk on shipboard without getting sick just as a rope-walker learns to walk on a high rope without getting dizzy. 'Through habit we learn to disregard those mistaken impressions which the semicircular canals send in - to be in a condition of "absent-mindedness" toward them. A sailor is in this condition so habitually that on returning to land after a long voyage he staggers for hours, even if he is not drunk.

\section{Clinical Department.}

A CASE OF GLYCOSURIA CAUSED BY A LESION PROBABLY SI'TUA'TED NEAR THE FOUR'TH VEN'TRICLE.'

$$
\text { BY A. K. B'TONI, M.D. }
$$

A GIRL, thirteen years old, of good family and personal history, had an alveolar abscess aud later an otitis media. 'This was followed by attacks of headache mostly located upon the left side. There was increase in thirst and in the amount of urine passed. During the beadaches there was diplopia. When first seen she had lost about seventeen pounds of flesh, was weak, with persistent headacho over the left eye, bowels constipated, skin harsh and dry. Paresis of the sixth nerve on the left side. Absence of all tendon reflexes. Urine: five pints, pale, and specific gravity 1,050 ; 10 albumen; sugar, nine per cent. by the polariscope. On limited diet she improved for a time, then the headuches became more severe and a general neuritis appeared. The muscles of the neck were tense. 'There was a return and exaggeration of all the reflexes and ankle clonus was present. During the starvation diet of the semi-conscious period, the sugar in the urine gradually fell until just before her death the analysis showed specific gravity 1,030 ; albumen a trace: sugar absent. 'Iwo days before death there was paralysis of the right side, with marked sigus of irritation on the left side, followed the next day with paralysis of tho left side.

As there was no autopsy the case was simply interesting from its probabilities. 'The persistent headache, the diplopia aud hemiplegia followed by paraplegia, would point to the head as the seat of the trouble, while the glycosuria, the left diplopia and crossed right paralysis would point to the viciuity of

1 Synopsis of a paper read bofore the Soation for Clintcal Mediclne, Puthology and Hygiene of tho Sulfolk District Medical Socloty, February 17, 1802. the pons, and the unexplained purulent otitis media would suggest that the lesion was tuberculous in origin.

Diabetes in children I found was confined to reports of one hundred and seventeen cases, while there are only eleven cases where glycosuria wus proved by tho autopsy to have been caused by tumor near the fourth ventricle.

\section{Reparte of Societieg.}

\section{MASSACHUSETTS MEDICAL SUCIE'TY. SUFFOLK DIS'TRICT.}

SECTION FOR CLINICAL MEDICINE, PATHOLOGY AND HYGIENE.

ALIBLTT N. BLODGK'N, M.D., BICCRITARY.

Regular meeting, Wednesday, February 17, 1892, Dr. E. G. Cutrer in the chair.

Dr. Gertrude W. Van Pelt read a paper on

CASES OF DYSPEPSIA, WITI TREATMENT BASED UPON aN EXaMination OF THE Gastric JUICE. ${ }^{1}$

Dr. A. L. Mason: I have been much interested in the cases. I notice she mentious that one patient did not get better until coffee had been abstained from. Is it usually found especially objectionable?

Dr. Van Pelt: I think that usually increases the secretion of hydrochloric acid.

Dr. Mason : Is it found necessary to give up coffee altogether in these cases?

Dr. VAn Pelt: In that one, where there was hypersecretion, it was given up for a short time only.

Dr. Mason : I have supposed coffee was troublesome for dyspeptic patients very often, but it seems harder to make them give it up than almost any other article they use. They miss, I suppose, its stimulating effect.

Dr. J. J. Putnam : I was quite interested in some of the cases which would ordinarily have been diagnosticated as nervous dyspepsia. It seems undoubtedly true that in many of these cases, although there is no distinct evidence of catarrhal disease without such examinations as these, nevertheless there is sometimes relief from the use of the stomach-tube. I have recently had one such case where the relief has been very marked indeed. I should like to ask whether there is any real reason to think the small doses of hydrochloric acid actually, by their acting as an acid on the food, help in the digestion, or whether they simply act by stimulating the stomach.

Dr. VAN Pelt: I think in both ways, but chiefly by stimulating the stomach to secrete.

Dr. Putnam: 'The quantity is so small it does not seem as if it could be of much use. I should like to ask whether the experiments that have been made in regard to the use of electricity in dyspepsia have shown anything more than a temporary increase of the secretion of gastric juice.

Dr. VAN PELT: I think the impression is that the nervous tone of the stomach is improved, though I suppose there have not been sufficient experiments to show exactly what it can do.

Dr. Putnam: I should like to ask whether electricity used in that way is distinctly more effectual than electricity used in other ways as a general tonic.

i Soe page 385 of the Journal. 